University of Nebraska - Lincoln

DigitalCommons@University of Nebraska - Lincoln

U.S. Environmental Protection Agency Papers

U.S. Environmental Protection Agency

2004

\title{
Special issue of Atmospheric Environment on findings from EPA's Particulate Matter Supersites Program
}

Constantinos Sioutas

University of Southern California

Spyros N. Pandis

Carnegie Mellon University

David T. Allen

University of Texas at Austin

Paul A. Solomon

U.S.EPA, solomon.paul@epa.gov

Follow this and additional works at: https://digitalcommons.unl.edu/usepapapers

Sioutas, Constantinos; Pandis, Spyros N.; Allen, David T.; and Solomon, Paul A., "Special issue of Atmospheric Environment on findings from EPA's Particulate Matter Supersites Program" (2004). U.S. Environmental Protection Agency Papers. 158.

https://digitalcommons.unl.edu/usepapapers/158

This Article is brought to you for free and open access by the U.S. Environmental Protection Agency at DigitalCommons@University of Nebraska - Lincoln. It has been accepted for inclusion in U.S. Environmental Protection Agency Papers by an authorized administrator of DigitalCommons@University of Nebraska - Lincoln. 


\section{Special issue of Atmospheric Environment on findings from EPA's Particulate Matter Supersites Program ${ }^{\text {t }}$}

In July 1997, the US Environmental Protection Agency (EPA) issued new National Ambient Air Quality Standards (NAAQS) for fine particulate matter $\left(\mathrm{PM}_{2.5}\right.$, atmospheric particles with aerodynamic diameters less than $2.5 \mu \mathrm{m}$ ). The $\mathrm{PM}_{2.5}$ NAAQS was developed by the EPA based on the results of numerous epidemiological studies that found persistent associations between outdoor concentrations of particulate matter (PM) and significant adverse health effects. However, considerable uncertainty existed concerning mechanisms by which various classes of particles might cause adverse health effects, as well as more detailed information on the composition and concentrations of ambient fine PM, that would be critical in implementing the new standards.

EPA recognized that an improved understanding of the key sources, development of the most cost/effective control strategies, and health risks associated with $\mathrm{PM}_{2.5}$ would depend on the availability of high-quality measurements of $\mathrm{PM}_{2.5}$ composition, size and, concentration over a variety of spatial and temporal scales. Yet many of the measurement methods for $\mathrm{PM}_{2.5}$, capable of resolving size and composition, had not been thoroughly evaluated nor previously deployed in regulatory monitoring networks. In response to this need, EPA embarked on an ambient monitoring research program, commonly referred to as the Particulate Matter Supersites Program (EPA, 2000). The primary goals of this program are:

(1) Characterize ambient particulate matter and related species at several locations throughout the US with differing atmospheric environments to elucidate sourcereceptor relationships and atmospheric processes. This will provide the scientific foundation for modeling and data analysis efforts that will support the development of state implementation plans (SIPs) and will develop more effective risk management approaches.

(2) Support health effects and exposure research by providing enhanced atmospheric measurements at ambient sites to obtain an improved understanding of the physical and chemical characteristics of aerosols. This information will help to reduce uncertainty

\footnotetext{
Text prepared by Paul A. Solomon.
}

in defining and implementing the NAAQS and improve the health-exposure research community's ability to address research questions and scientific uncertainties about PM source-receptor-exposure-effects relationships.

(3) Conduct methods testing to compare, evaluate, and help validate emerging and routine methods for characterizing PM. Results will help to define and quantify methods uncertainty, identify methods suitable for routine monitoring, and to further support the first two goals.

The Supersites Program combines a mix of intensive or advanced measurements at a central location combined with other monitoring sites. A Supersites Project should not be viewed solely as a single site making research grade measurements, but as part of the overall PM monitoring program that is supported spatially and temporally by the national criteria pollutant monitoring networks, other national networks (e.g., $\mathrm{PM}_{2.5}$ National Speciation Trends Network, STN), and special studies funded by public and private organizations. The Supersites Program consists of three phases. In Phase I, EPA selected two initial sites: Atlanta GA and Fresno CA. These sites were noncompetitively selected by virtue of (1) ongoing and planned research activities that closely aligned with those of the PM Supersites Program and (2) distinctly different airsheds (e.g., atmospheric chemistry, sources, etc.). In Phase II, seven additional sites were competitively selected with cooperative agreements awarded in January 2000. The Phase II Supersites Projects were located in Baltimore, MD; Fresno, CA; Houston, TX; Los Angeles, CA; New York, NY; Pittsburgh, PA; and St. Louis, MO. Detailed descriptions of the Supersites Projects are available at the EPA Supersites Program web page http://www.epa.gov/ttn/amtic/supersites. $\mathrm{html}$ ). Phase III, now underway, includes the development of an integrated relational database containing air quality and meteorological data nationally from the end of June 2001-August 2002 (http://supersitesdata. umd.edu/), the completion of the NARSTO data archive (http:// eosweb.larc.nasa.gov/PRODOCS/narsto/table_ narsto. $\mathrm{html}$ ), integrated data analysis, and the development of a key and policy relevant findings document. 
This collection of papers, which is the second coordinated publication of results from the Phase II Supersites Program, reflects the objectives of the program - to characterize particulate matter, to provide information supporting health effects and exposure research, and to develop new methods for characterizing fine particulate matter. Papers describe results from Supersites Projects in Pittsburgh, PA; Houston, TX; Los Angeles, CA; New York, NY; Baltimore, MD; sites in the southern US that were associated with the Atlanta Supersites Project; and results from the STN in two Supersites Program locations. A Phase I Supersites Program special issue describing results from Atlanta is published (Solomon et al., 2003). The first Phase II Supersites Program special issue is published in Aerosol Science and Technology (Solomon and Allen, 2004). Additional coordinated publication of research results is planned, so that the community interested in airborne PM can effectively monitor the advances in understanding PM in air made through the Supersites Program. The next special issue is underway in Journal of Geophysical Research-Atmospheres with a publication date in early 2005. Subsequent second special issues are anticipated in each of these journals during 2005 and 2006.

A summary of the key and policy relevant findings follow:

\section{Characterize ambient PM}

Wittig, Anderson, et al. (this issue) provide an overview of the Pittsburgh Supersites Project-Pittsburgh Air Quality Study (PAQS). Key findings summarized, some of which are described or supported in more detail in this special issue, include:

- $\mathrm{PM}_{2.5}$ comprises a significant fraction of the $\mathbf{P M}_{10}$ mass in all months (Cabada et al., this issue).

- The annual average $\mathrm{PM}_{2.5}$ mass concentration at the core site was $15.5 \mu \mathrm{g} / \mathrm{m}^{3}$ and, thus, unofficially exceeded the annual average standard for $\mathrm{PM}_{2.5}$. The 24-h standard was not exceeded, with the peak daily concentration only reaching $60.5 \mu \mathrm{g} / \mathrm{m}^{3}$.

- Seasonal variations in $\mathrm{PM}_{2.5}$ mass and composition are driven by differences in the seasonal variations of organic carbon and sulfate, with sulfate being dominant in the summer and organic matter (OM) and sulfate showing similar concentrations in the cooler months (Rees et al., this issue).

- In the cooler months, nitrate also is important and approximately equal to about half the sulfate concentration on average (Rees et al., this issue).

- Lack of a diurnal pattern in seasonally averaged (July and January) $\mathrm{PM}_{2.5}$ mass and similar concentrations at satellite sites upwind and downwind of Pittsburgh suggest that much of the $\mathrm{PM}_{2.5}$ is transported into the Pittsburgh area.

- Approximately 35\% of the organic aerosol in the summer was estimated to be secondary in nature (Cabada et al., 2004).

- Regional nucleation events are observed on clean bright sunny days, where nucleation seems to be initiated by sulfuric acid, ammonia, and water and particle growth due to condensation of sulfates, organic compounds, and water.

In general, PM mass and chemical composition followed expected trends in the east versus the west (Chu et al., this issue). In Fresno, $\mathrm{PM}_{2.5}$ was clearly identified as a wintertime problem with the major components being organic material and nitrate. In Atlanta, the highest concentrations were observed in the summer with sulfate being the largest contributor, although organic carbon was abundant year round. At other eastern locations, the aerosol is characterized by higher sulfate and secondary $\mathrm{OC}$ in the summer and higher overall $\mathrm{OC}$ and nitrate in the winter months (Wittig et al., this issue; Rees et al., this issue; Tanner et al., this issue). At all locations, OM seems to be a fairly consistent and major fraction of the $\mathrm{PM}_{2.5}$ year round accounting for $20-40 \%$ of the $\mathrm{PM}_{2.5}$ mass. Results also indicate that a significant fraction of the sulfate and organic carbon in urban areas in the eastern US is regional and transported into the cities from upwind areas (Cabada et al., this issue; Modey et al., this issue; Gaffney et al., this issue; Dutkiewicz et al., this issue; Tanner et al., this issue), although locally derived primary organic carbon also can be an important contributor to $\mathrm{PM}_{2.5}$ in urban areas, being superimposed on regional aerosol levels. Also, $\mathbf{P M}_{2.5}$ mass and number concentrations $(3-560 \mathrm{~nm}$ size range) are not correlated (Stanier et al., this issue), indicating that $\mathrm{PM}_{2.5}$ mass cannot act as a surrogate for number concentration, which is important if health effects are associated with ultrafine particles, since only $\mathrm{PM}_{2.5}$ mass and its chemical components are measured in routine national monitoring networks.

The regional nature of PM in the Eastern US can significantly influence accumulation of particles over time. Measurements at an upwind site and the central site, Cabada et al. (this issue) indicate that about $90 \%$ of the sulfate at the Pittsburgh core site in July is due to transport from upwind areas. Broad size distributions for OC and EC with peaks at about $0.45 \mu \mathrm{m}$ also indicate the influence of long-range transport for these constituents. Modey et al. (this issue) using measurements obtained at the National Energy and Technology Laboratory (NETL) and at the core site in Pittsburgh show that high $\mathrm{PM}_{2.5}$ episodes were generally associated with transport of pollutants during the transition from high pressure to low-pressure meteorological regimes. 
Measurements of radionuclides in the Pittsburgh area (Gaffney et al., this issue), from which aerosol residence time is estimated, indicate that a significant fraction of the fine particulate matter observed in the Pittsburgh area is transported 1-3 weeks. In NY, sulfate concentrations are reasonably uniform over hundreds of kilometers indicating the regional nature of sulfate in the northeast (Dutkiewicz et al., this issue). On an annual basis, transport from upwind areas accounts for nearly $50 \%$ of the sulfate measured at the Queens urban site and about $60 \%$ at the rural and backgrounds sites, Pinnacle and Whiteface Mountain, respectively. Highest sulfate concentrations at all three sites were observed with air apparently transported from the Ohio River Valley and the Great Lakes Basin.

In the summer, at the Pittsburgh core-sampling site (Wittig, Takahama, et al., this issue), most of the total nitrate is in the gas phase during the day and in the particulate phase during the night with maximum concentrations in the early morning before sunrise. Almost all the available total nitrate is in the particulate phase in the winter. Sulfate concentrations, show little consistent diurnal variation throughout the year, except in the summer, when sulfate peaks slightly during the afternoon due to photochemical production. Using single particle mass spectrometry (SPMS) data from the RSMS III at the Baltimore Supersites Project, Tolocka et al. (ultrafine nitrate in Baltimore, this issue) observed two types of ultrafine (UF) nitrate particle events, both of which are accompanied by an increase in the number of mixed composition particles containing nitrate, suggesting condensation of ammonium nitrate onto pre-existing particles. Events are associated with colder more humid weather indicating the role of thermodynamics in the gas-particle partitioning of ammonium nitrate.

Secondary inorganic and organic aerosols can be important contributors to ambient $\mathrm{PM}_{2.5}$ concentrations. Results from several Supersites Projects indicate the greater influence of sulfate aerosols and secondary $\mathrm{OC}$ in the summer, when photochemical activity peaks, and more organic and nitrate aerosols in the winter, with lower mixing heights and cooler temperatures (Cabada et al., this issue). In Texas, Russell and Allen (this issue) indicate peak primary OC and EC occur in the winter along with maximum concentrations of other primary pollutants, however, peak secondary OC occurs in September, when ozone has its highest concentrations. On average, maximum monthly primary and secondary OC fall into the same range of about $10-20 \%$ each of $\mathrm{PM}_{2.5}$, and thus, are of about equal importance in terms of their contribution to OC in fine PM in SE TX. In Los Angeles, Miguel et al. (this issue), also indicate an increase in secondary organic aerosol formation in the summer relative to the cooler months. PAH size distributions in Los Angeles depend on the volatility of the $\mathrm{PAH}$, with lower volatility $\mathrm{PAH}$ compounds partitioning into the aerosol phase with decreasing temperature.

Several papers focused on components of organic aerosols. Yue and Fraser (this issue) report on concentrations of polar organic aerosols and indicate how these species can be used to identify sources of OC, including wood smoke (levoglucosan), higher molecular weight acids ( $>$ C22) suggesting contribution from biogenic sources, and carboxylic diacids correlating with unapportioned $\mathrm{OC}$ by $\mathrm{CMB}$ indicating secondary organic aerosol formation. Miguel et al. (this issue) examined the distribution of PAH species in UF, fine, and coarse modes and examined differences in their distributions between warmer months and cooler months. Size distributions in the summer months were similar for reported $\mathrm{PAH}$, however, in the cooler months, a significant fraction of the $\mathrm{PAH}$ mass was observed in the coarse $\left(\mathrm{PM}_{2.5}-\mathrm{PM}_{10}\right)$ mode.

Regional nucleation events were observed on about $30 \%$ of the days during the Pittsburgh Supersites Project (Stanier et al., 2004). These were observed on clean sunny days in both the central urban and a rural site. During the study, number concentration $(<100 \mathrm{~nm})$ at urban sites was about 2-3 times that at rural sites due to the impact of local sources (motor vehicle traffic). By $200 \mathrm{~nm}$ both size distributions were similar, illustrating the regional nature of fine PM in the eastern US. Ultrafine (UF) chemical composition in Pittsburgh varies between winter and summer (Cabada et al., this issue). In the summer, $50 \%$ of the UF aerosol is organic, while $40 \%$ is ammonium sulfate. In the winter, $70 \%$ appears to be organic and only $25 \%$ ammonium sulfate with minimal amounts of nitrate and crustal components.

Tolocka et al. (number concentrations in metals, this issue) use number concentrations of 4 trace metals (V, $\mathrm{Fe}, \mathrm{As}$, and $\mathrm{Pb}$ ) obtained using single particle mass spectrometry (RSMS III) and meteorological data at the Baltimore Supersites Project to identify sources based on the individual spectra. Their new approach to pre-select spectra based on an above-threshold signal intensity at a specified $\mathrm{m} / \mathrm{z}$ allows for improved partitioning of spectra into specific classes using neural network methods. Metals are typically observed in short-term bursts rather than long-term steady concentrations. For $\mathrm{Fe}, \mathrm{Pb}$, and As, concentrations are a function of wind direction. Vanadium is observed from all wind directions and implies a relatively wide distribution of fuel oil combustion in the area.

Particle-bound water appears to be an important constituent of fine aerosol mass in the summertime in Pittsburgh. Stanier et al. (2004) indicate the aerosol is more hygroscopic in the summer than the winter, likely due to the higher levels of inorganic water-soluble species in the summer, and higher levels of primary 
organic carbon in the winter. The hygroscopic behavior of size resolved PM was measured at three sites in Houston (Gasparini et al., this issue) during the summer and early fall of 2001. Hygroscopicity increased with increasing particle size, which suggests that condensation of organic compounds onto the smallest particles measured are responsible for initial growth, while further growth was achieved by condensation of sulfuric acid and other inorganic species. This is consistent with results from Pittsburgh regarding nucleation events that appear to be initiated by nucleation of sulfuric acid/ ammonia/water followed by growth due to condensation of sulfates, organic compounds, and water (Stanier et al., 2004). By comparing the FRM PM 2.5 mass to the sum of the chemical components collected with the CMU speciation sampler, after correcting for sampling artifacts, Rees et al. (this issue) indicate that the largest differences, up to $30 \%$, occur in the summer when higher aerosol loadings are observed. In these cases, the aerosol is composed of ammonium bisulfate $\left(\mathrm{NH}_{4} \mathrm{HSO}_{4}\right)$, is acidic, and has the highest amount of water associated with the particles, versus the winter, when the mass balance is within a few percent, and the aerosol is composed of higher fractions of organics and ammonium nitrate, along with ammonium sulfate $\left(\left(\mathrm{NH}_{4}\right)_{2} \mathrm{SO}_{4}\right)$. During some winter days, with relatively high nitrate or high OC concentrations, the sum of components also can be higher than the FRM mass. The negative bias appears to be due to volatilization. A method for the calculation of the water concentration on the filter is proposed and evaluated. These results suggest that both retention of water and volatilization of semi-volatile species from the FRM filter need to be considered to obtain an improved estimate of $\mathrm{PM}_{2.5}$ concentrations in air.

Motor vehicle emissions were estimated during the Houston Supersites Project from tunnel measurements (McGaugher et al., this issue). Emissions estimates from the tunnel agree well with modeled data (Mobile 5b and 6) for all NOx and NMOC, but Mobile 6 emissions estimates for $\mathrm{CO}$ from gasoline vehicles were a factor of two high relative to tunnel results and Mobile 5b. It was noted in the paper that this difference has been observed previously.

\section{Conduct methods testing}

The development and evaluation of methods is a primary objective of the Supersites Program. Significant advances have been made in the development and evaluation of new and existing methods to quantify PM mass and composition, precursor species, and other related species and parameters. Testing of continuous methods has been a major effort across several of the Supersites Projects, including extensive efforts to better define the uncertainty (bias and precision) associated with the methods evaluated and their operational characteristics. At the Pittsburgh Supersites Project, Wittig, Takahama et al. (this issue) evaluated and characterized the commercial R\&P nitrate (R\&P model $8400 \mathrm{~N}$ ) and sulfate (R\&P model 8400S) flash volatilization monitors. The importance of evaluating these newly available commercial methods is critical before use in national monitoring networks. Through their evaluation, these investigators apply standard corrections to the raw data of the continuous sulfate and nitrate monitors tested to account for instrument drift, conversion efficiency, and other factors. After instrument calibration, values for nitrate and sulfate are still low by $17 \%$ and $29 \%$, respectively, relative to the filter-based methods, which for nitrate and sulfate are believed to have minimum bias based on the methods employed. Correlation coefficients for both sulfate and nitrate relative to the filter-based methods are reasonably high with $R^{2}$ of about 0.85 . To obtain final data for analysis, Wittig, Takahama et al. (this issue) calibrate the continuous methods against the filter-based methods. The final data, which closely agree with the filter-based methods, are then used to characterize short-term variations in these species in the area.

Laser-Induced Breakdown Spectroscopy (LIBS) is used to measure the distribution of seven elements in single ambient aerosol particles at the Pittsburgh Supersites Project core-sampling site (Lithgow et al., this issue). This is the first long-term (8-days) continuous use of LIBS to measure multiple inorganic species in air. Results show a potential for this method to quantify multiple elements in single particles at very low levels, suggesting that data from LIBS might be potentially useful in source apportionment studies.

In collecting size resolved chemical composition data, Cabada et al. (this issue) indicate substantial losses of OC $(50 \%)$ and nitrate $(70 \%)$ from MOUDI samplers in Pittsburgh using Al foil collection plates in the summer, but not in the winter. Previous impactor studies in the Western US (Hering et al. (1997) and references within) comparing impactor results to filter-based methods have shown little loss of nitrate from the impactor samples, but similar loss for OC, although for the latter, lower OC MOUDI values were observed throughout the year rather than just in the summer as observed in Cabada et al. In both studies, the adsorption of gas phase organics onto quartz-fiber filters was accounted for in the filter-based methods. Differences in ambient temperature and $\mathrm{RH}$, concentrations of the semi-volatile compounds, and operating conditions among the different studies can probably explain the different results.

Chakrabarti et al. (this issue) evaluate the performance of an active DataRAM $\mathrm{PM}_{2.5}$ mass monitor 
designed for continuous personal exposure measurements. Results indicate good precision, but there is a strong, expected, and predictable dependence on relative humidity, which can be accounted for if $\mathrm{RH}$ data are available. The active feature relative to the passive monitor evaluated previously allow for collection of a back-up filter for gravimetric mass determination. Good agreement is obtained for $\mathrm{PM}_{2.5}$ on the back-up filter relative to the FRM and to the 24-h averaged $\mathrm{RH}$-corrected continuous personal dataRAM.

An important quality assurance tool is described by $\mathrm{Yu}$ et al. (this issue) for evaluating discordant outliers in scanning mobility particle sizer (SMPS) data. The approach includes both a graphic presentation and statistical analysis. From the results they are able to identify $0.021 \%$ of the data (out of approximately 10 million data points) that should be further examined as being suspect. The approach appears to be successful at the four locations where measurements were obtained, showing the robustness of the technique.

Positive Matrix Factorization (PMF) is applied to $\mathrm{PM}_{2.5}$ mass and composition data including the eight individual carbon fractions reported from thermal optical reflectance (TOR, IMPROVE method, Chow et al., 1993) for daily samples collected in Atlanta, GA during August 1998-August 2000. Improved source identification is obtained over the use of traditional OC and EC variables due to the use of TOR fractions, especially for the separation of diesel and gasoline vehicle emission sources. Identification of local point sources is further enhanced by inclusion of surface wind data.

\section{Support health effects and exposure research}

Many of the results from these papers are applicable to health effects and exposure studies. For example, papers in this special issue describe the consistency of the major constituents on regional scales, perhaps suggesting why similar health effects are observed in different urban environments. Results also provide information on primary and secondary pollutants, including secondary organic aerosol as well as the impact of particlebound water in accounting for $\mathrm{PM}_{2.5}$ mass. Primary organic aerosols appear to peak in the winter along with nitrate, including potentially toxic lower volatility PAH species. The description of nucleation bursts on regional scales, and the identification of the composition during formation and growth, suggests that large populations may be exposed to high concentrations of ultrafine PM on clean days where fresh particles may begin as an external mixture of sulfates and organic particles, but become internally mixed with carbonaceous material during the day.

\section{Policy relevant findings}

Based on the results described above, the following policy relevant findings can be noted:

- The regional nature of fine sulfate and organic carbon in the eastern US suggests the need for regional strategies to reduce PM mass levels in urban areas, although local sources of carbon also are important contributors to PM in urban areas.

- In Pittsburgh, ambient barometric pressure transitions from high to low pressure might be a predictor of the occurrence of fine PM episodes in the midAtlantic region.

- Diurnal partitioning of nitrate observed in Pittsburgh and Baltimore indicate that sufficient $\mathrm{HNO}_{3}$ is present year round to impact PM fine mass in the east, especially during the winter months. In addition, these results suggest the possibility of nitrate substitution, whereby reductions in $\mathrm{SO}_{2}$ reduce ammonium sulfate, allowing available ammonia to be scavenged by $\mathrm{HNO}_{3}$, and thus, losing some of the benefit in $\mathrm{PM}$ fine mass reductions from $\mathrm{SO}_{2}$ reductions.

- Under the conditions tested during the one year study in the Pittsburgh area, the continuous commercial nitrate and sulfate analyzers manufactured by R\&P and based on flash volatilization required calibration against the filter-based methods to provide results with minimal bias relative to the filter-based results. This supports the earlier recommendation by the Clean Air Scientific Advisory Panel (CASAC, 2002) that filter-based methods be replaced by continuous methods as soon as possible, and as suggested during the meeting, while maintaining a subset of sites with filter-based measurements, albeit perhaps on a lower frequency than collected currently. The CASAC recommendation was only for PM2.5 mass, but these results suggest this might be useful for implementing measurements by continuous speciation methods as well.

- The composition of UF particles in the east appear to vary, with significantly more OC in the UF mode in the winter and more ammonium sulfate in the summer. In either case, OC and ammonium sulfate comprise most of the UF mass. As well, nucleation bursts are regional in nature and results suggest they are initiated by nucleation of sulfuric acid, ammonia, and water followed by growth due to adsorption of organics and water.

- Results from the Pittsburgh Supersites Project, suggest that both retention of water and volatilization 
of semi-volatile species from the FRM filter need to be considered to obtain an improved estimate of $\mathrm{PM}_{2.5}$ concentrations in air.

\section{Acknowledgements}

The United States Environmental Protection Agency through its Office of Research and Development partially funded and collaborated in the research described here under Assistance agreement Nos. CR8280257-01 (Desert Research Institute, Reno, NV), CR8280258-01-0 (Washington University, St. Louis, MO), CR8280259-01-0 (University of California, Los Angeles, CA), CR8280260-01-0 (State University of New York, New York, NY), CR8280261-01-0 (Carnegie Mellon University, Pittsburgh, PA) CR8280262-01-0 (University of Texas, Austin, TX), and CR8280263-01-0 (University of Maryland, Baltimore, MD). It has been subjected to Agency review and approved for publication. Mention of trade names or commercial products does not constitute endorsement or recommendation for use by EPA.

\section{References}

Cabada, J.C., Pandis, S.N., Subramanian, R., Robinson, A.L., Polidori, A., Turpin, B., 2004. Estimating the secondary organic aerosol contribution to $\mathrm{PM}_{2.5}$ using the EC tracer method. Aerosol Science \& Technology, 38(S1), in press.

CASAC, 2002. Review of the Agency's draft Continuous Monitoring Implementation Plan; a Review by the Clean Air Scientific Advisory Committee, March 1. US EPA, Washington, DC. http://www.epa.gov/ttn/amtic/files/ ambient/pm25/casac/casac102001.pdf.

Chow, J.C., Watson, J.G., Pritchett, L.C., Pierson, W.R., Frazier, C.A., Purcell, R.G., 1993. The DRI thermal/optical reflectance carbon analysis system: Description, evaluation and applications in U.S. air quality studies. Atmospheric Environment 27A (8), 1185-1201.
EPA, 2000. PM Supersites Program Background. Available at: http://www.epa.gov/ttn/amtic/files/ambient/super/ssback. pdf, 07-01-00.

Hering, S.V., Eldering, A., Seinfeld, J.H., 1997. Bimodal character of accumulation mode aerosol mass distributions in Southern California. Atmospheric Environment 31 (1), $1-11$.

Solomon, P.A., Allen, D., 2004. Preface: Special Issue of Aerosol Science and Technology On Findings from the Fine Particulate Matter Supersites Program. In: Allen, D., Pandis, S., Sioutas, C., Hopke, P., Solomon, P.A. (Eds.), Aerosol Science \& Technology, 38(S1).

Solomon, P.A., Cowling, E., Weber, R. (Eds.), 2003. The 1999 Atlanta Supersites Project, Preface to Special Issue. Journal of Geophysical Research-Atmospheres, Special Issue for the Atlanta Supersites Project, 108(D7), 8428, doi:10.1029/ 2003JD003536.

Stanier, C., Khloystov, A., Pandis, S.N., 2004. Nucleation events during the Pittsburgh Air Quality Study: description and relation to key meteorological, gas phase and aerosol parameters, Aerosol Science \& Technology, 38(S1), in press.
Constantinos Sioutas (Guest editor) University of Southern California, Los Angeles, CA, USA

Spyros N. Pandis (Guest editor) Carnegie Mellon University, Pittsburgh, PA, USA

David T. Allen (Guest editor) University of Texas, Austin, TX, USA

Paul A. Solomon (Guest editor) US EPA, ORD 944E. Harmon, Rm. 235, Las Vegas, NV, USA E-mail address: solomon.paul@epa.gov 